\title{
Desempenho de novilhas Holandês na produção de embriões F1 Holandês-Zebu, em condições tropicais
}

\section{Performance of Holstein heifers for F1 Holstein-Zebu embryo production, in tropical conditions}

\author{
Bruna Rios Coelho Alves,,,** José Reinaldo Mendes Ruas,, ${ }^{* *}$ Thiago Fernandes Amaral,,* \\ Samuel Guedes Borges da Silva, ${ }^{* *}$ Guilherme Pugliesi, ${ }^{* \star *}$ José Monteiro da Silva Filho, ${ }^{* *}$ Álan Maia Borges ${ }^{\star *}$
}

\begin{abstract}
Resumo
A produção in vivo de embriões bovinos é uma alternativa para a formação e manutenção de rebanhos mestiços $\mathrm{F} 1$ destinados à produção de leite. Objetivou-se estudar o potencial de utilização de novilhas da raça Holandês, mantidas em pasto e suplementadas, como doadoras de embrião, nas épocas de verão e inverno. Procederam-se superovulação e coleta de embriões em sete novilhas em cada época. Foram obtidos os dados climáticos, a temperatura retal e a frequência respiratória das doadoras. No verão, observou-se maior índice de temperatura e umidade (ITU) às $6 \mathrm{~h}, 12 \mathrm{~h}$ e $18 \mathrm{~h}$, bem como maior $(P<0,05)$ temperatura retal das doadoras às 18h. A porcentagem de animais que respondeu à superovulação foi de $71,4 \%(5 / 7)$ no inverno e $85,7 \%$ (6/7) no verão. O número total de estruturas recuperadas por doadora variou de um a 49 no inverno, e de zero a 23 no verão. Não houve diferença $(P>0,05)$ na média de estruturas recuperadas $(20,14 \pm 17,47$ vs. $8,57 \pm 9,40)$, embriões viáveis $(14,57 \pm 11,91$ vs. $7,14 \pm 7,24)$ e congeláveis $(13,28 \pm 11,39$ vs. $6,57 \pm 6,24)$ obtidos no inverno e no verão, respectivamente. Sob as condições estudadas, novilhas da raça Holandês podem ser utilizadas para a produção de embriões F1, tanto no verão, quanto no inverno.
\end{abstract}

Palavras-chave: transferência de embriões, novilhas, época do ano, superovulação.

\begin{abstract}
In vivo embryo production (embryo transfer) is an alternative for F1 dairy herds formation and maintenance. The aim of this study was to evaluate the potential of utilization of grazing and supplemented Holstein heifers as embryo donors in summer or winter. Superovulation was performed in seven heifers on each season. Climatic parameters, as well as rectal temperature and respiratory rate of donors were measured. Temperature and humidity index $(\mathrm{THI})$ was higher $(\mathrm{p}<0.05)$ in summer at 6:00, $12: 00$ and 18:00, as rectal temperature at 18:00. Response to superovulation was observed in $71.4 \%(5 / 7)$ and $85.7 \%(6 / 7)$ of donors in winter and summer, respectively. Total ova/embryo recovered varied from 1 to 49 in winter and 0 to 23 in summer. Average ova/embryo, viable and freezable embryo was respectively, $20.14 \pm 17.47 ; 14.57 \pm 11.91$ and $13.28 \pm 11.39$ in winter and $8.57 \pm 9.40 ; 7.14 \pm 7.24$ and $6.57 \pm 6.24$ in summer $(P>0.05)$. Holstein heifers can be used as embryo donors in both summer and winter, under the given conditions.
\end{abstract}

Keywords: embryo transfer, heifers, season, superovulation.

\section{Introdução}

Animais obtidos a partir do cruzamento F1 Holandês $x$ Zebu apresentam maior eficiência econômica para a produção de leite em relação a outros cruzamentos, em condições tropicais (Madalena et al., 1990). No entanto, a reposição contínua desse genótipo, em rebanhos leiteiros, ainda é um desafio a ser estabelecido. A produção in vivo de embriões, mais comumente denominada transferência de embriões (TE), é uma alternativa a ser considerada para a formação e manutenção de rebanhos que visam utilização de fêmeas F1 para a produção de leite.
Os parâmetros climáticos observados em diferentes épocas do ano podem influenciar a produção de embriões a partir da superovulação, principalmente em animais taurinos. Tal fato relaciona-se com a maior susceptibilidade dessa subespécie ao estresse calórico, decorrente das altas temperatura e umidade ambiente observadas na época de verão em países de clima tropical. Os efeitos deletérios da hipertermia são bastante pronunciados durante as primeiras clivagens do embrião (Putney et al., 1989; Ealy et al., 1993). Até sete dias de gestação, embriões apresentam alta sensibilidade ao estresse calórico (Hansen e Ealy, 1991)

\footnotetext{
* Embrapa Gado de Leite - R. Eugênio do Nascimento, 610 - 36038-330 - Juiz de Fora, MG. E-mail: bruna@cnpgl.embrapa.br.

** Departamento de Clínica e Cirurgia Veterinárias/UFMG - Belo Horizonte, MG.

*** CTZM-EPAMIG - Viçosa, MG.

${ }^{* * * *}$ Departamento de Zootecnia da UFV - Viçosa, MG.
} 
sendo que sua resistência a esse tipo de estresse aumenta à medida que se desenvolvem (Edwards e Hansen, 1997).

Vacas em lactação são mais susceptíveis ao estresse calórico (Sartori et al., 2002). Além disso, sofrem aumento das concentrações plasmáticas e intra-foliculares de metabólitos deletérios à qualidade dos oócitos e, consequentemente, à dos embriões (Leroy et al., 2004). Isso se relaciona com a menor qualidade de estruturas recuperadas a partir da superovulação de vacas em lactação (Sartori et al., 2002, Leroy et al., 2005). Por outro lado, além de serem mais tolerantes a temperaturas elevadas, novilhas não sofrem os efeitos da lactação, sendo, portanto, alternativa para a produção de embriões F1 a partir da base materna Holandês, em diferentes épocas do ano.

O objetivo deste trabalho foi estudar o potencial de utilização de novilhas da raça Holandês como doadoras de embrião, nas épocas de verão e inverno, em condições tropicais.

\section{Material e métodos}

O experimento foi conduzido na Fazenda Experimental Prof. Hélio Barbosa (FEPHB), pertencente à Escola de Veterinária da Universidade Federal de Minas Gerais (UFMG), situada

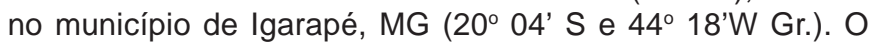
período experimental compreendeu duas épocas do ano: inverno (26/07/2006 a 20/08/2006) e verão (17/01/2007 a 04/ 02/2007).

Foram utilizadas 14 novilhas da raça Holandês, sete no inverno e sete no verão, com idade, peso e escore de condição corporal de $23,8 \pm 3,4$ meses, $355,8 \pm 43,6 \mathrm{~kg}$ e $3,4 \pm 0,5$, respectivamente. A seleção das doadoras baseou-se no exame ginecológico realizado por meio da palpação transretal, sendo utilizadas aquelas que apresentaram pelo menos dois ciclos estrais regulares prévios e ausência de qualquer alteração clínica ou reprodutiva.

As novilhas foram mantidas em piquete de capim elefante (Pennisetum purpureum Schum.), sendo oferecidos sal mineral à vontade e $2 \mathrm{~kg}$ de ração concentrada, por animal, em cocho coletivo coberto. Adicionalmente, durante o inverno as doadoras receberam de silagem de milho (Zea mays) ad libitum e $2 \mathrm{~kg}$ de polpa cítrica por animal.

Durante o período experimental foram obtidas a pluviosidade e as temperaturas máximas e mínimas diárias, além das temperaturas de bulbo seco e úmido em três momentos diários (6h, $12 \mathrm{~h}$ e 18h), utilizando-se pluviômetro presente na fazenda e termômetros de máximas e mínimas, e de bulbo seco e úmido, localizados em local coberto próximo ao piquete onde se localizavam os animais. A umidade relativa do ar (UR) foi calculada a partir das temperaturas de bulbo seco e úmido, segundo Silva (2000). O índice de temperatura e umidade (ITU) foi calculado pela seguinte fórmula: ITU = $0,72 \times(B S+B U)+40,6$; sendo BS a temperatura do bulbo seco e BU a temperatura do bulbo úmido (PIRES et al., 1999). A temperatura retal (TR) e a frequência respiratória (FR) também foram mensuradas às $6 \mathrm{~h}, 12 \mathrm{~h}$ e $18 \mathrm{~h}$.

A superovulação das doadoras foi realizada segundo o protocolo: inserção de dispositivo intravaginal contendo $1,9 \mathrm{~g}$ progesterona, ${ }^{1}$ independentemente da fase do ciclo estral

${ }^{1}$ CIDR - Pfizer, Brasil. (dia 0), e aplicação de $2 \mathrm{mg}$ de Benzoato de Estradiol $^{2}$ pela via intra-muscular (IM) no dia 1. A aplicação (IM) de $\mathrm{FSH}^{3}$ iniciou-se no dia 5 , sendo administradas oito doses decrescentes intervaladas de 12 horas totalizando $400 \mathrm{UI}$ distribuídas conforme descrito a seguir: $20 \%, 20 \%, 15 \%, 15 \%$, $10 \%, 10 \%, 5 \%$ e $5 \%$. Concomitantemente à sétima dose, foi administrado (IM) 0,5mg de Cloprostenol Sódico, ${ }^{4}$ sendo o dispositivo intravaginal retirado no momento da aplicação da última dose de FSH. Após a retirada do dispositivo foi realizada observação do estro três vezes ao dia $(6 \mathrm{~h}, 12 \mathrm{~h}$ e $18 \mathrm{~h})$, por 60 minutos, com auxílio de rufião. Os animais foram submetidos a três inseminações artificiais (IA) a cada de 12 horas, iniciando-se 12 horas após a detecção do estro, utilizando-se sêmen comercial de touros da raça Gir, de fertilidade comprovada.

As coletas dos embriões foram realizadas nos dias 6 ou 7 após a primeira IA. No dia da coleta, as doadoras foram avaliadas por palpação transretal para a estimativa do número de corpos lúteos em cada ovário. Considerou-se que houve resposta à superovulação quando as doadoras apresentaram mais de dois corpos lúteos à palpação. Fêmeas com ausência de corpo lúteo em ambos ovários não foram submetidas à coleta de embriões. Este procedimento foi realizado em tronco coberto, pelo método não-cirúrgico, em sistema fechado. Uma sonda de Foley ${ }^{5}$ foi introduzida e fixada no corpo uterino para a lavagem simultânea dos cornos uterinos. Para cada doadora, foram utilizados $1000 \mathrm{~mL}$ do meio Dulbecco Modificado. ${ }^{6}$ As estruturas recuperadas foram avaliadas sob estereomicroscópio e classificadas, de acordo com seu estádio de desenvolvimento e qualidade, segundo Linder e Wright (1983).

Os dados de temperatura máxima e mínima, temperatura ambiente, umidade relativa do ar (UR) e índice de temperatura e umidade (ITU), obtidos nos diferentes horários durante os processos de superovulação e coleta de embriões; bem como idade, peso e intervalo da retirada do dispositivo intravaginal de progesterona e ao estro, foram submetidos à análise de variância, considerando-se o efeito fixo de tratamento, e as médias comparadas entre as duas épocas do ano pelo teste F. Para a comparação da FR e TR, foram considerados os valores obtidos nos seguintes dias: inserção do dispositivo intravaginal de progesterona, início das aplicações de $\mathrm{FSH}$, retirada do dispositivo intravaginal de progesterona, e dia do estro até a coleta dos embriões. Procedeu-se a análise de variância desses dados, considerando-se os efeitos de época, dia da mensuração e sua interação, sendo as médias comparadas pelo teste $\mathrm{F}$. Os resultados da coleta dos embriões (número de estruturas totais, viáveis, congeláveis, degeneradas e não fecundadas, e de embriões excelentes, bons e regulares) foram analisados pelo teste de Wilcoxon. As análises foram realizadas utilizando-se o programa estatístico SAEG (Fundação Arthur Bernardes - UFV), versão 9.1.

\footnotetext{
${ }^{2}$ Estrogin - Farmavet, Brasil.

${ }^{3}$ Pluset - Calier, Espanha.

${ }^{4}$ Ciosin - Shering-Plought, Brasil.

${ }^{5}$ Rusch, Malásia.

${ }^{6}$ DMPBS - Nutricell, Brasil.
} 


\section{Resultados e discussão}

Os parâmetros climáticos referentes às duas épocas de produção dos embriões encontram-se na Tabela 1.

Tabela 1: Parâmetros climáticos durante os períodos experimentais de inverno e verão (média \pm desvio-padrão), na Fazenda Experimental Prof. Hélio Barbosa (FEPHB

\begin{tabular}{|c|c|c|c|c|}
\hline \multirow{2}{*}{ Parâmetro } & \multicolumn{2}{|c|}{ Inverno } & \multicolumn{2}{|c|}{ Verão } \\
\hline & Média $\pm \mathrm{s}$ & Variação & Média $\pm \mathrm{s}$ & Variação \\
\hline Temperatura máxima $\left({ }^{\circ} \mathrm{C}\right)$ & $28,9 \pm 1,7^{a}$ & $24,0-31,5$ & $26,5 \pm 1,6^{b}$ & $23,0-29,0$ \\
\hline Temperatura mínima $\left({ }^{\circ} \mathrm{C}\right)$ & $13,1 \pm 1,9^{b}$ & $9,0-17,0$ & $19,5 \pm 0,8^{a}$ & $18,0-21,0$ \\
\hline Temperatura $6 \mathrm{~h}\left({ }^{\circ} \mathrm{C}\right)$ & $13,6 \pm 1,6^{b}$ & $10,5-16,5$ & $20,5 \pm 0,8^{a}$ & $19,0-22,0$ \\
\hline Umidade Relativa $6 \mathrm{~h}(\%)$ & $86,2 \pm 12,4^{b}$ & $36,0-100$ & $93,6 \pm 3,0^{a}$ & $87,3-100$ \\
\hline ITU às $6 \mathrm{~h}$ & $59,3 \pm 2,1^{b}$ & $55,0-62,9$ & $69,9 \pm 1,1^{a}$ & $67,2-71,6$ \\
\hline Temperatura $12 \mathrm{~h}\left({ }^{\circ} \mathrm{C}\right)$ & $27,7 \pm 2,5^{a}$ & $22,0-32,0$ & $25,2 \pm 1,8^{b}$ & $21,0-28,0$ \\
\hline Umidade Relativa 12h (\%) & $38,3 \pm 12^{b}$ & $9,5-71,8$ & $80,7 \pm 6,4^{a}$ & $71,0-95,6$ \\
\hline ITU às $12 \mathrm{~h}$ & $73,4 \pm 2,6^{b}$ & $67,2-77,3$ & $75,0 \pm 2,1^{a}$ & $70,5-79,5$ \\
\hline Temperatura $18 \mathrm{~h}\left({ }^{\circ} \mathrm{C}\right)$ & $23,9 \pm 2,6^{b}$ & $16,0-28,0$ & $26,2 \pm 2,4^{a}$ & $21,0-30,0$ \\
\hline Umidade Relativa 18h(\%) & $47,7 \pm 18,5^{b}$ & $7,1-88,3$ & $78,0 \pm 9,3^{a}$ & $58,1-95,6$ \\
\hline ITU às $18 \mathrm{~h}$ & $69,7 \pm 3,0^{b}$ & $60,8-75,5$ & $76,1 \pm 2,5^{a}$ & $70,5-79,1$ \\
\hline
\end{tabular}

Pluviosidade total durante o período $(\mathrm{mm})$

4,1

a,bMédias na mesma linha, seguidas por letras distintas, diferem entre si pelo teste $F(P<0,05)$.

As médias das temperaturas ambiente e do ITU obtidas nos horários das 12 horas, nas duas épocas, e no horário das $18 \mathrm{~h}$, no verão, foram superiores aos limites estabelecidos para conforto térmico de bovinos, que são de $25^{\circ} \mathrm{C}$ (Shearer e Beede, 1990) e 72 (Armstrong, 1994), para temperatura ambiente e ITU, respectivamente. Logo, os animais permaneceram sob condições ambientais potencialmente estressantes nas duas épocas. Além disso, durante o verão, a exposição a essas condições ocorreu por período mais longo, com valores que ultrapassaram os limites de conforto tanto às 12 horas, quanto às 18 horas.

A FR das novilhas foi maior $(P<0,05)$ no verão em relação ao inverno, nos três horários analisados (Figura 1).

Segundo Shearer e Beede (1990), a partir de $21^{\circ} \mathrm{C}$ de temperatura ambiente, bovinos passam a utilizar a evaporação através das vias respiratórias como principal forma de dissipação de calor. Assim, as médias de temperatura ambiente acima de $20,5^{\circ} \mathrm{C}$, e os maiores valores de UR e de ITU, observados no verão, se relacionam com a maior FR das novilhas nessa época. O aumento na FR foi, provavelmente, eficiente para a dissipação do calor às $6 \mathrm{~h}$ e $12 \mathrm{~h}$, pelo fato de que as temperaturas retais se mantiveram semelhantes nas duas épocas $(P>0,05)$ (Figura 2). No entanto, às $18 \mathrm{~h}$, observou-se maior $(P<0,05)$ TR no verão em relação ao inverno, o que pode estar relacionado com o
166,0

maior ganho e a menor eficiência de perda de calor por evaporação, em decorrência do elevado ITU observado nesse horário, durante o verão.

Todas as fêmeas, durante o inverno, apresentaram estro após a retirada do dispositivo intravaginal de progesterona, enquanto que no verão, uma não apresentou. A percentagem de animais que responderam à superovulação foi de $71,4 \%$ (5/7) no inverno e $85,7 \%$ (6/7) no verão. Os dois animais que não responderam à superovulação, no inverno, apresentaram um ou dois corpos lúteos no dia da coleta, sendo recuperados um e dois embriões respectivamente, de cada doadora. No verão, a doadora que não respondeu à superovulação não apresentou nenhum corpo lúteo no dia da coleta e, portanto, não foi submetida a esse procedimento.

Segundo Hahn (1992), cerca de 20 a 30\% dos animais não respondem ao tratamento superovulatório. Trabalhos com superovulação em novilhas da raça Holandês reportaram que 84,0\% (Ax et al., 2005) e $87,8 \%$ (Chagas e Silva et al., 2002) desses animais produziram embriões, independentemente da quantidade recuperada. A eficiência da superovulação observada no presente trabalho assemelha-se à registrada pelos autores acima, porém, neste estudo o parâmetro utilizado para avaliar se houve resposta à superovulação foi a produção de um número maior que dois corpos lúteos nos ovários, visto que novilhas, ocasionalmente, podem apresentar duplas ovulações (Sartori et al., 2004).

$\mathrm{O}$ intervalo da retirada do dispositivo intravaginal à detecção do estro foi de $33,4 \pm 11,6$ horas, não sendo observada diferença entre as duas épocas $(P>0,05)$. Esse valor é semelhante ao reportado por Lafri et al. (2002), de 31,9 \pm $0,7 \mathrm{~h}$ entre a retirada do CIDR e a observação do estro.

A comparação entre as épocas do ano em relação às estruturas recuperadas não apontou diferença $(P>0,05)$ em nenhuma das categorias avaliadas (Tabela 2). Tal fato pode estar relacionado com a característica da resposta à superovulação, de elevado coeficiente de variação (Peixoto et al., 2006). Este padrão de resposta pode ser atribuído à instabilidade de variáveis que envolvem resposta hormonal (Sampaio, 2002) conforme pode ser observado no desvio padrão das variáveis (Tabela 2) e, também, à grande variação individual no número de folículos ovarianos (Monniaux et al., 1983), fator associado à capacidade de resposta à superestimulação. 


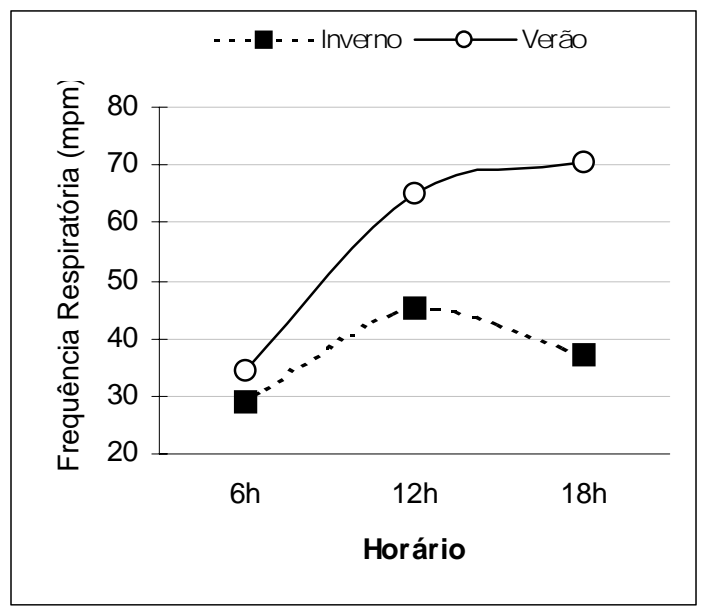

${ }^{*} \mathrm{P}<0,05$

Figura 1: Frequência respiratória média de doadoras, às $6 \mathrm{~h}, 12 \mathrm{~h}$ e $18 \mathrm{~h}$, no inverno e verão

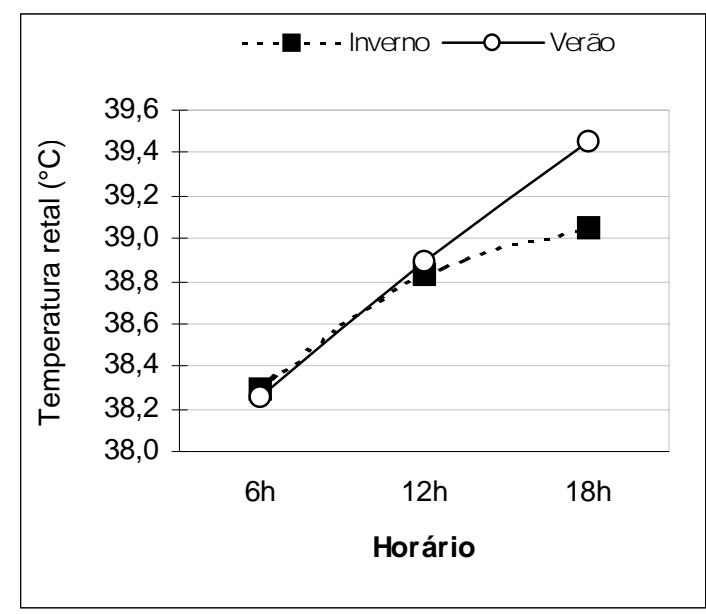

${ }^{*} \mathrm{P}<0,05$

Figura 2: Temperatura retal média das doadoras às $6 \mathrm{~h}$, $12 \mathrm{~h}$ e $18 \mathrm{~h}$, no inverno e verão do assim, a temperatura ambiente e umidade observadas nas duas épocas, podem não ter provocado aumento na temperatura corporal das doadoras com intensidade suficiente para ocasionar efeitos deletérios à produção e desenvolvimento embrionários de magnitude mensurável no presente delineamento. Tal fato também pode estar relacionado com a maior capacidade de novilhas (em relação a vacas) em controlar o aumento da temperatura cor-
Tabela 2: Estruturas recuperadas a partir da superovulação de doadoras da raça Holandês nas épocas de inverno e verão

\begin{tabular}{|c|c|c|c|c|c|c|}
\hline \multirow{2}{*}{$\begin{array}{c}\text { Estruturas } \\
\text { recuperadas }\end{array}$} & \multicolumn{3}{|c|}{ Inverno } & \multicolumn{3}{|c|}{ Verão } \\
\hline & Total & Média \pm s & $\%$ & Total & Média $\pm \mathrm{s}$ & $\%$ \\
\hline Excelente (grau 1) & 68 & $9,7 \pm 10,2$ & 48,2 & 37 & $5,3 \pm 4,9$ & 61,6 \\
\hline Boa (grau 2) & 25 & $3,6 \pm 3,1$ & 17,7 & 9 & $1,3 \pm 1,5$ & 15,0 \\
\hline Regular (grau 3) & 9 & $1,3 \pm 2,1$ & 6,4 & 4 & $0,6 \pm 1,5$ & 6,7 \\
\hline Degenerada & 27 & $3,9 \pm 6,7$ & 19,2 & 6 & $0,9 \pm 1,5$ & 10,0 \\
\hline Não fecundada & 12 & $1,7 \pm 2,6$ & 8,5 & 4 & $0,6 \pm 1,1$ & 6,7 \\
\hline $\begin{array}{l}\text { Total } \\
\text { (Variação) }\end{array}$ & 141 & $\begin{array}{c}20,1 \pm 17,5 \\
(1 \text { a } 49)\end{array}$ & 100,0 & 60 & $\begin{array}{c}8,6 \pm 9,4 \\
(0 \text { a } 23)\end{array}$ & 100,0 \\
\hline Viáveis $(1,2$ e 3$)$ & 102 & $14,6 \pm 11,9$ & 72,3 & 50 & $7,1 \pm 7,2$ & 83,3 \\
\hline Congeláveis ( 1 e 2 ) & 93 & $13,3 \pm 11,4$ & 65,9 & 46 & $6,6 \pm 6,2$ & 76,6 \\
\hline
\end{tabular}

Médias na mesma linha não diferem entre si pelo teste de Wilcoxon $(P>0,05)$.

Segundo Rodrigues (2001), 30\% das doadoras produzem um número de embriões viáveis superior a sete. Neste trabalho, $57 \%(8 / 14)$ das coletas resultaram na recuperação de mais de sete estruturas. Além disso, as médias de embriões viáveis/coleta (14,6 e 7,1 no inverno e verão, respectivamente) foram superiores às reportadas na literatura para novilhas da raça Holandês, de 6,4 (Chagas e Silva et al., 2002) e 4,7 (AX et al., 2005). Fatores como a condição nutricional das doadoras (Gong et al., 2002), ou à dose de FSH utilizada no protocolo podem estar relacionados com a resposta obtida no presente experimento.

A percentagem de estruturas viáveis e a predominância de estruturas excelentes (grau 1) recuperadas nas duas épocas indicam que a maior temperatura retal das doadoras observada às $18 \mathrm{~h}$ no verão não acarretou redução na qualidade dos embriões. Rivera e Hansen (2001) reportaram que danos aos embriões provocados por estresse calórico ocorreram a partir de sua exposição a temperaturas superiores $\left(40,5^{\circ} \mathrm{C}\right)$ às observadas nesse experimento. Sen- poral em decorrência do aumento progressivo da temperatura ambiente (Sartori et al., 2002). Putney et al. (1989) observaram que a redução da qualidade e desenvolvimento de embriões de novilhas da raça Holandês superovuladas ocorreu quando a temperatura ambiente máxima atingiu valores superiores a $32,2^{\circ} \mathrm{C}$, durante os sete dias antecedentes à recuperação dos embriões. No presente trabalho, a temperatura ambiente observada situouse abaixo desse limiar. Finalmente, a utilização de sêmen proveniente de raça zebuína para a inseminação das doadoras também pode ter contribuído para aumentar a resistência dos embriões a temperaturas elevadas, assim como observado in vitro (Eberhardt et al., 2005).

Alguns autores reportaram que noviIhas superovuladas produzem menor número de estruturas em relação a vacas (Kanuya et al., 1997; Callesen et al., 1998), ou que poderia haver maior dificuldade para transposição de cérvix nesses animais durante a coleta (Hasler et al., 1983), sendo estes fatores, portanto, desvantagens da escolha dessa categoria como doadoras de embrião. Por outro lado, outros trabalhos mostraram que novilhas, tanto da raça Holandês (Ax et al., 2005) quanto mestiças Holandês-Zebu (Borges et al., 2001) produziram embriões viáveis em número compatível com o reportado em trabalhos com animais adultos (Tonhati et al., 1999; Chagas e Silva et al., 2002; Hasler, 2003). O número de estruturas viáveis recuperadas no presente trabalho também mostrou que a superovulação de novilhas, nas condições estudadas, produz resultados satisfatórios.

\section{Conclusão}

Novilhas da raça Holandês podem ser utilizadas para a produção de embriões F1 Holandês - Zebu, tanto no inverno, quanto no verão. 


\section{Agradecimento}

À FAPEMIG, pelo financiamento do projeto (CAG 1153/05).

\section{Referências}

ARMSTRONG, D.V. Heat stress interaction with shade and cooling. J. Dairy Sci., v. 77, p. 2044-2050, 1994.

AX, R. L.; ARMBRUST, S.; TAPPAN, R.; et al. Superovulation and embryo recovery from peripubertal Holstein heifers. Anim. Reprod. Sci. , v. 85, p. 71-80, 2005.

BORGES, A. M.; TORRES, C. A. A.; RUAS, J. R. M. et al. Resposta superovulatória de novilhas mestiças holandês-zebu tratadas com somatotropina bovina recombinante (rbST). Rev. Bras. Zoot., v. 30, p. 1439-1444, 2001.

CALLESEN, H.; GREVE, T.; AVERY, B. Embryo technology in cattle: brief review. Acta. Agric. Scand., v. 29, p. 19-29, 1998.

CHAGAS e SILVA, J.; LOPES DA COSTA, L.; ROBALO SILVA, J. Embryo yield and plasma progesterone profiles in superovulated dairy cows and heifers. Anim Reprod. Sci, v. 69, p. 1-8, 2002.

EALY A.D.; DROST M.; ROBINSONO. W. et al. Developmental changes in embryonic resistance to adverse effects of maternal heat stress in cows. J. Dairy Sci., v. 76, p. 2899-2905, 1993.

EBERHARDT, B. G.; SATRAPA, R. A.; CAPINZAIK, R. L. et al. M. Influencia da raça do touro e da raça da vaca na resistência de embriões bovinos estresse térmico in vitro, durante a fase inicial de desenvolvimento. Acta Sci. Vet., v. 33, p. 362, 2005 (resumo).

EDWARDS, J.L.; HANSEN, P.J. Differential responses of bovine oocytes and pre-implantation embryos to heat shock. Mol. Reprod. Dev., v. 46, p. 138-145, 1997.

GONG, J. G.; ARMASTRONG, D. G.; BAXTER, G. et al. The effect of increased diretary intake on superovulatory response to $\mathrm{FSH}$ in heifers. Theriogenology, v. 57, p. 1591-1602, 2002.

HAHN, J. Attempts to explain and reduce variability of superovulation. Theriogenology, v. 38, p. $269-265,1992$.

HANSEN, P.J., EALY, A.D. Effects of heat stress on the establishment and maintenance of pregnancy in cattle. In: CONGRESSO BRASILEIRO DE REPRODUÇÃO ANIMAL, 9., 1991, Belo Horizonte. Anais... Belo Horizonte: CBRA, 1991. p. 108-119.

HASLER, J. F.; MACCAULEY, A. D.; SCHERMERHORN, E. C.; Foote, R. $\mathrm{H}$. Superovulatory responses of Holstein cows. Theriogenology, v. 9, p. 353-362, 1983.

HASLER, J. F. The current status and future of commercial embryo transfer in cattle. Anim. Reprod. Sci., v. 79, p. 245-264, 2003.

KANUYA, R.; CALLESEN, H.; HYTTEL, P. et al. Superovulatory response of dairy cattle (Bos taurus) in a tropical environment. Theriogenology, v. 47, p. 1583-1593, 1997.

LAFRI, M.; PONSART, C. NIBART, M. et al. Influence of CIDR treatment during superovulation on embryo production and hormonal patterns in cattle. Theriogenology, v. 58, p. 1141-1151, 2002.

LEROY, J.; VANHOLDER, T.; DELANGHE, J. et al. Metabolic changes in follicular fluid of the dominant follicle in high-yielding dairy cows early post partum. Theriogenology, v. 62 , p. 1131-1143, 2004.
LEROY, J.; OPSOMER,G.; DE VLIEGHER, S. Comparison of embryo quality in high yielding dairy cows, in dairy heifers and in beef cows. Theriogenology, v. 64, p. 2022-2036, 2005.

LINDNER, G. M.; WRIGHT, W. Bovine embryo morphology and evaluation. Theriogenology, v. 20, p. 407-416. 1983.

MADALENA, F.E.; LEMOS, A.M.; TEODORO, R.L. et al. Dairy production and reproduction in Holstein-Friesian and Guzera crosses. J. Dairy Sci., v. 73, p. 1872-1886, 1990.

MONNIAUX, D.; CHUPIN, D.; SAUMANDE, J. Superovulatory responses of cattle, Theriogenology, v.19, p. 55-82, 1983.

PEIXOTO, M. G. C. D,; BERGMANN, J. A. G.; FONSECA, C. G. et al. Effects of environmental factors on multiple ovulation of zebu donors. Arq. Bras. Med. Vet. Zootec., v. 58, p. 567-574, 2006.

PIRES, M. F. A.; FERREIRA, A, M., COELHO, S.G. Estresse calórico em bovinos de leite. Cad. Tec. Vet. Zootec., v. 29, p. 23-37, 1999.

PUTNEY, D.J.; MULLINS, S.; THATCHER, W. W. et al. Embryonic development in superovulated dairy cattle exposed to elevated ambient temperature between the onset of estrus and insemination. Anim. Reprod. Sci. , v. 19, p. 37-51, 1989.

RIVERA, R. M.; HANSEN, P. J. Development of cultured bovine embryos after exposure to high temperatures in the physiological range. Reproduction, v. 121, p. 107-115, 2001.

RODRIGUES, J. L. Transferência de embriões bovinos - histórico e perspectivas atuais. Rev. Bras. Reprod. Anim, v. 25, p. 102-107, 2001.

ROSERKRANS, K. S.; HARDIN, D., K. Repeatability and accuracy of reproductive tract scoring to determine pubertal estrus in beef heifers. Theriogenology, v. 4, p. 1087-1092, 2003.

SAMPAIO, I.B.M. Estatística Aplicada à Experimentação Animal. 2. ed. Belo Horizonte: FEPMVZ, 2002. 221 p.

SARTORI, R.; SARTOR-BERGFELT, R.; MERTENS, S. A. et al. Fertilization and early embryonic development in heifers and lactating cows in summer and lactating and dry cows in winter. J. Dairy Sci., v. 85, p. 2803-2812, 2002

SARTORI, R.; HAUGHIAN, J. M.; SHAVER, R. D. et al. Comparison of ovarian function during the estrous cycle of Holstein heifers and lactating cows. J. Dairy Sci. v. 87, p. 905-920, 2004.

SHEARER, J. K.; BEEDE, D. K. Thermoregulation and physiological responses of dairy cattle in hot weather. Agri-practice, v. 11, p. 5-17, 1990.

SILVA, R. G. Introdução à Bioclimatologia Animal. São Paulo: Nobel, 2000. $286 \mathrm{p}$.

TONHATI, H.; LOBO, R. B.; OLIVEIRA, H. N. Repeatability and heritability of response to superovulation in Holstein cattle. Theriogenology, $\mathrm{v}$. 51, p. 1151-1156, 1999. 